\title{
Comprehension Monitoring Characteristics and Level of Proficiency: A Study of Iranian EFL Learners
}

\author{
Elahe Mahmoudi ${ }^{1}$ \\ ${ }^{1}$ University of Mazandaran, Babolsar, Iran \\ Correspondence: Elahe Mahmoudi, Department of English language and literature, University of Mazandaran, \\ Babolsar, Iran. Tel: 98-111-326-1080. E-mail: ek.mahmoudi@yahoo.com
}

Received: May 9, 2014 Accepted: June 1, $2014 \quad$ Online Published: June 17, 2014

doi:10.5430/ijelt.v1n2p64 URL: http://dx.doi.org/10.5430/ijelt.v1n2p64

\begin{abstract}
Integrating both qualitative-quantitative approaches this study examined how language learners with different proficiency levels monitor reading comprehension when dealing with academic texts. To this end, a standard reading test was administered to 115 freshman university students to identify those with high and low reading proficiency levels. Two groups, more proficient readers and less proficient readers, each consisting 5 learners emerged. Concurrent verbal protocols, error detection and retrospective questions were employed to obtain multiple measures of participants' monitoring strategy use. Analysis of participants' reports on comprehension monitoring use during reading academic texts, the results of t-tests, and percentages of comprehension monitoring use among the two groups suggested that there is a relationship between reading proficiency and this particular strategy. More proficient readers outdid less proficient readers in frequency of comprehension monitoring strategy use. Also, less proficient readers performed comprehension monitoring poorly and less frequently in comparison with more proficient readers in that they were unsuccessful in examining whether the employed strategies were helpful in overcoming their reading problems.
\end{abstract}

Keywords: reading comprehension, monitoring, level of proficiency

\section{Introduction}

Psychologists interested in how individuals learn have devoted much attention to the cognitive processes involved in encoding, storing, and retrieving information of all types, as well as comprehending the complex information with which they are confronted daily. Investigators have examined a variety of cognitive processes, with particular attention to memory and language comprehension, and have tried to expand our understanding of the factors that lead to enhanced comprehension during reading.

As mentioned in Loizidou and Koutselini, 2007, in the current declaration of the European Union's strategic tasks for the year 2010 (European Committee, 2003), it is clearly evident that developing students' metacognitive skills is of great importance since it has a direct relationship with enabling lifelong learning and active social enactment among students. In a similar vein, the metacognitive task described as helping 'students to learn how to learn' has been declared by UNESCO as the highest educational priority (UNESCO, 2002, cited in Loizidou and Koutselini, 2007).

According to Hetherington and Parke, (1993, p.367) "one reason that many investigators are currently interested in metacognition is because of its relevance to educational problems such as reading." Poor readers have been shown to have metacognitive deficits in a wide variety of the aspects of reading (Baker, 1985). They are less likely than better readers to spend more time on difficult passages, to review the passages learned, and to adapt their reading activities to the demands and goals of the reading task. They do not redeploy their effort in a task-adaptive manner over time.

Comprehension monitoring is one aspect of metacognitive control in reading comprehension (Baker \& Brown, 1984; Brown, 1987; Hacker, 1997; Oakhill, Hartt, \& Samols, 2005; Wagoner, 1983) which is a process by which an individual evaluates the state of his/her understanding of information" (Oakhill, Hartt, \& Samols 2005, p. 658), and it "directs the reader's cognitive processes as he/she strives to make sense of incoming textual information" (Wagoner, 1983, p. 328). It is the awareness of whether comprehension is occurring and the conscious application of appropriate strategies to correct comprehension (Zipke, 2007). Brown (1987) postulated that effective 
comprehension monitoring requires a balance of both automatic and controlled processes. When comprehension is occurring smoothly, the process is automatic without much conscious attention; but when a "trigger event" takes place, controlled processing is activated to "debug" comprehension breakdowns.

As mentioned previously, the primary goal of metacognitive monitoring is to detect a lack of comprehension so that it can be corrected. As soon as readers realize that they do not comprehend whatever they are reading, they use fix-up strategies to try to compensate for that. These corrective strategies consist of rereading, asking for help from others, using reference materials such as dictionary, reading an additional text, making logical inferences within the text or from background knowledge, making a diagram, or reading ahead to try to make sense of it (Pressley \& Afflerbach, 1995). Also, strategies such as summarizing, general questions and predictions are associated with monitoring (Cromely, 2005).

Having these issues in mind, this study intends to examine the manifestation of comprehension monitoring among proficient and less-proficient readers. The study indirectly stresses the point that the more we understand the thought processes in our students, the better we as teachers can instruct our lessons to reflect all the ways our students are decoding whatever we are trying to teach. If we can read up-to- date research on how our students are thinking and how they are learning about what they are thinking we can adjust our delivering accordingly.

\section{Literature Review}

\subsection{Studies on Comprehension Monitoring and Reading Comprehension}

To date, most of the research concerning comprehension monitoring has been conducted with native speakers of English (Baker \& Brown, 1984; Flavell, 1981; Markman, 1981; Zabrucky \& Ratner, 1992). However, the comprehension monitoring of foreign language readers has not been well documented and there is a dearth of studies in which comprehension monitoring process of EFL readers has been investigated. This is while it can be claimed that comprehension monitoring is of utmost importance for EFL readers. First of all, due to lack of consistent exposure to written foreign discourse EFL readers encounter more problems in understanding authentic, unmodified written materials. Consequently, they might need to "repair more gaps" (Block, 1992) in their understanding than L1 readers.

Studies on the comprehension monitoring of English native speakers abound. These studies have usually employed an error detection paradigm, in which readers' comprehension monitoring was examined with a task that required them to detect errors embedded in a text (Garner, 1987). These errors included nonsense words (lexical inconsistencies), information that violates general knowledge (i.e., external inconsistencies), and information that is contradictory within the text itself (i.e., internal inconsistencies) (Oakhill, Hartt, \& Samols, 2005). It has been found that the detection of 'internal inconsistencies' tends to be more difficult than the detection of 'external inconsistencies' (e.g., Ehrlich, Remond, \& Tardieu, 1999). In order to detect an internal inconsistency, readers must first encode and store the relevant information, draw necessary inferences, and construct a global text representation. They must then be able to evaluate the incoming information against that representation, retrieve the incompatible proposition and then compare the two propositions. For detection of an external inconsistency, readers only need to understand sentences at a local level, and then make a comparison between information in the sentence and their general knowledge, which is likely to be more stable than information just gained from the text (Baker \& Zimlin, 1989; Ehrlich, Remond, \& Tardieu, 1999; Markman, 1985; Oakhill, Harrt, \& Samols, 2005; Otero \& Kintsch, 1992, cited in Stevenson and Han, 2008).

L1 studies have also examined the contribution of comprehension monitoring to reading comprehension. Zinar (2000) examined the contributions of both word identification skills and comprehension monitoring and found that word recognition made a larger contribution than comprehension monitoring, which made a small but significant contribution to the prediction of $\mathrm{L} 1$ reading comprehension.

As the review of the literature reveals, there is little research on comprehension monitoring in FL reading. Among the few existing studies, most investigated the process of readers' comprehension monitoring by using think-aloud protocols (Jiménez, García, \& Pearson, 1996; Stevenson \& Han, 2008; Yang, 2002).

Stevenson and Han (2008) conducted a study of comprehension monitoring of Chinese lower intermediate EFL (English as a foreign language) learners in first language (L1) and foreign language (FL) reading. They investigated the outcome of comprehension monitoring in L1 and FL reading, as well as the separate contributions of L1 reading proficiency and FL comprehension monitoring to FL reading proficiency. 126 students in the vocational department of a foreign languages university in China participated in the study. They completed a Chinese and an English error 
detection task, in which they were asked to read two texts in each language embedded with external and internal inconsistencies. Measures of Chinese and English reading proficiency were obtained from the mid-term examinations. Four of the 126 readers also participated in retrospective interviews in which they explained the basis on which they had identified the textual inconsistencies and also offered possible corrections. Quantitative data from the two error detection tasks and the reading scores were analyzed using repeated measures ANOVA (Analysis of Variance) and multiple regression analysis. Supplementary qualitative data from the retrospective interviews were analyzed using content analysis. The results showed that participants performed significantly better in comprehension monitoring in L1 reading than in FL reading. They also showed that FL comprehension monitoring made a small, unique contribution to FL reading proficiency, but that L1 reading proficiency made a much larger contribution. The results suggest that metacognitive control does play a role in FL reading.

Block (1992) conducted a study concerning the comprehension monitoring of L1 and L2 readers as they read an expository text. There were four groups in the study including $16(8 \mathrm{~L} 1$ and $8 \mathrm{~L} 2$ readers) being classified as proficient and 9 ( $3 \mathrm{~L} 1$ and $6 \mathrm{~L} 2$ readers) as non proficient. Two specific problems were implemented to discuss monitoring, one involving a search for a referent and the other a vocabulary problem. Three phases and six specific steps of: evaluation phase (problem recognition and problem source identification), action phase (strategic plan and action/ solution attempt), and checking phase (check and revision) have been defined. She analyzed responses and they showed that monitoring was most thorough with the referent problem when the problem was explicitly signaled. There were two primary findings. First, during monitoring a referent problem, proficient L1 and L2 readers involved in comprehension monitoring processes in the same way. Likewise, both less proficient L1 and L2 readers were more likely to fail to recognize that a problem existed or identify the source and solve the problem. It showed that reading proficiency is definitely a factor in determining the success of readers' comprehension monitoring processes.

In the second place, when monitoring a vocabulary problem, both proficient L1 and L2 readers performed comprehension monitoring in the same way as they did a referent problem.

Block further concluded that differences in the efficiency of comprehension monitoring between the four groups is in their reading proficiency, rather than their language background.

Other studies have shown that students who use metacognitive strategies, such as those who monitor their reading comprehension, adjust their reading rates, consider the objectives and so on tend to be better readers. A two-part first language study by Paris and Meyers (1981) was carried out to examine comprehension monitoring and study of strategies of good and poor readers. The initial part of their study investigated the differences in comprehension monitoring between good and poor fourth grade readers during an oral reading of a story. Their ability to monitor comprehension of difficult anomalous information was measured by spontaneous self-corrections during oral reading, by directed underlining of incomprehensible words and phrases, and by study behaviors. Their study demonstrated that poor readers do not engage in accurate monitoring as frequently as good readers. Furthermore, poor readers also demonstrated less accurate comprehension and recall of the stories than good readers. The second phase of their study was conducted to provide additional information about the differences between good and poor readers' comprehension skills. The researchers paid particular attention to children's strategies for deriving meaning for difficult vocabulary words. It was found that good readers used comprehension strategies far more frequently than poor readers. For example, good readers wrote notes and summaries related to the text. The children were also asked to define specific vocabulary words. Most good readers reported using strategies of asking questions or referring to the dictionary to determine word meaning; while none of the poor readers did so. Poor readers were more concerned with the pronunciation of words rather than meanings. Overall, poor readers engaged in a few spontaneous study behaviors, failed to ask questions, take notes or use a dictionary as often as good readers. High proficient readers, on the other hand, used cognitive, memory, metacognitive, compensation, and social strategies to a far greater extent than low proficient readers. Although the above discussion pertaining to reading strategies and second language learning is by no means exhaustive, it does provide one with an overview of the kinds of investigations and range of studies that have been carried out by researchers in this area.

From the above findings of research in reading strategies, it becomes clear that there are indeed differences between successful or good readers, and less successful or poor readers in terms of comprehension monitoring. There is also a strong relationship between reading strategies used by readers and proficiency level. Overall, successful readers or high proficient readers, appear to be using a wider range of strategies. Moreover, these readers also appear to use strategies more frequently than less successful or poor readers. Results of some studies have also shown that successful readers know when and how to apply reading strategies on a given task. 


\section{The Current Study}

This study intended to delineate the probable difference between comprehension monitoring of more proficient and less proficient Iranian EFL readers. Accordingly, the following research question was identified and guided this study:

Are there any differences between more proficient readers (MP) and less proficient readers (LP) in terms of the quantity and quality of comprehension monitoring performance?

To empirically study the proposed research question, the following null hypothesis is mentioned:

There is no difference between MP and LP learners in terms of the quantity and quality of comprehension monitoring performance.

\section{Methodology}

\subsection{Participants of the Study}

The subjects who participated in this study were selected from among 115 volunteer students majoring in electronics in Babol University of Technology (BUT), Mazandaran, Iran. They were freshmen who attended general English classes. They were both males and females and their age range was 19-20. To make sure of the homogeneity of the sample in terms of general English proficiency, a proficiency test (TOEFL) was administered to all 115 students and the mean of their scores was calculated. The students whose scores were 1 SD above and below the mean score were selected as subjects. Then, 80 out of 115 were identified to be at the same level of language proficiency and were chosen for the next step of sample selection. In the next part, they were administered a reading comprehension test of Longman's TOEFL test (1996, second edition by Deborah Phillips). Based on the results of the Reading comprehension test of Longman's TOEFL test, those participants having highest and lowest scores in reading comprehension test were chosen and grouped into More Proficient readers (MP) and Less Proficient readers (LP), 5 (MP) and 5 (LP).

\subsection{Instrumentation}

Qualitative-quantitative design was adopted in the present research. Due to the nature of this study, qualitative design was used in which through data triangulation it was tried to obtain multiple measures of participants' comprehension monitoring strategies. In fact, three methods of think-aloud, error detection paradigm and retrospective questions were manipulated in data collection procedure. The error-detection technique was employed to investigate the nature of comprehension monitoring. This procedure defines the evaluation component of comprehension monitoring operationally as the ability to identify successfully errors introduced intentionally into an intact text and the regulation component as the ability to deploy remedial strategies for comprehension failure (Zabrucky \& Ratner, 1992).

The monitoring ability of readers was assessed by detecting the inconsistent information. They are asked to report, explain the nature of the errors and reasons for the answers after reading text silently or loudly. They displayed regulation by changing the errors and through behaviors such as looking back at text read earlier. Through specifically worded questions, evaluation and regulation of errors were elicited. The questions that helped with process were as follow: "Does everything make sense?" or "If something doesn't make sense, what change would you make?" or globally worded questions such as" Did the story make sense?" (Zebrucky \& Ratner, 1992 cited in Ling, 2000). The next tool was think-aloud technique. The thinking aloud technique was manipulated as a procedure to investigate on-line cognitive processing. It was used to explore the nature of reading comprehension processes and reading strategies use. The rationale for using it in comprehension monitoring research was that thinking aloud during reading not only reflects comprehension monitoring but also represents a form of comprehension monitoring itself (Baumann et al., 1993). Think-aloud procedures produce concurrent verbalization about an activity that is temporarily interrupted for provision of the verbal report. Readers stop reading periodically to say aloud what they are processing, what they understand and the reading strategies they are using (Baumann et al., 1993). The instruction such as "Tell me what you are thinking and doing while you read this article" elicits this process. The recorded verbalization on audiotape for analysis is then transcribed and categorized and finally irrelevant information in protocols is discarded (Garner, 1987b).

Retrospective questions were used to tap into students' comprehension monitoring strategies reportedly used in reading the passage and detecting the error. Here, too, students' responses were recorded and transcribed for inter-rater coding. 


\section{Results}

\subsection{Statistical Results Concerning the Difference among MP and LP in Comprehension Monitoring}

To answer the proposed research question, first t-test was used to determine whether the means of MP group and LP group were equal.

Table 1. Independent Samples t-test for MP and LP groups

\begin{tabular}{|c|c|c|c|c|c|c|c|c|}
\hline & $\begin{array}{l}\text { Levene's Test } \\
\text { for Equality of } \\
\text { Variances }\end{array}$ & t-test 1 & r Equalit & of Means & & & & \\
\hline & $\begin{array}{ll}\text { F } & \text { Sig. }\end{array}$ & $\mathrm{t}$ & $\mathrm{df}$ & Sig.(2-tailed) & $\begin{array}{l}\text { Mean } \\
\text { Difference }\end{array}$ & $\begin{array}{l}\text { Std. Error } \\
\text { Difference }\end{array}$ & \multicolumn{2}{|c|}{$\begin{array}{l}95 \% \text { Confidence } \\
\text { Interval of the } \\
\text { Difference }\end{array}$} \\
\hline Frequency & & & & & & & Lower & Upper \\
\hline $\begin{array}{l}\text { Equal } \\
\text { variances } \\
\text { assumed }\end{array}$ & $1.12 \mathrm{E} 1$ & 3.406 & 66 & .001 & .815 & .239 & .337 & 1.293 \\
\hline $\begin{array}{l}\text { Equal } \\
\text { variances } \\
\text { not } \\
\text { assumed }\end{array}$ & & 3.826 & $6.55 \mathrm{E} 1$ & .000 & .815 & .213 & .390 & 1.240 \\
\hline
\end{tabular}

As it is clearly depicted in table (1) Levene's test of equality of variances shows that sig $=.001$ and since it is less than 0.05 , the null hypothesis that "There is no difference between MP and LP learners in terms of the quantity and quality of comprehension monitoring performance" is rejected. This is in fact what is further verified by confidence interval of differences (.390-1.240) within which no 0 can be found.

To explore further to see where the difference(s) in comprehension monitoring of proficient and less proficient readers lie(s), cross tabulation was used to calculate the frequency and percentage of using the six subcomponents of comprehension monitoring strategies among more proficient and less-proficient readers.

Table 2. Monitoring Strategies among MP and LP Groups

Monitoring strategies*Group crosstabulation

\begin{tabular}{|c|c|c|c|c|c|c|}
\hline \multirow[b]{3}{*}{ Monitoring strategies } & \multirow[b]{3}{*}{ Determining the word } & & & \multicolumn{2}{|c|}{ Group } & \multirow[b]{2}{*}{ Total } \\
\hline & & & & MP & LP & \\
\hline & & $\begin{array}{l}\text { Count } \\
\% \text { within }\end{array}$ & Monitoring & $\begin{array}{l}7 \\
43.8 \%\end{array}$ & $\begin{array}{l}9 \\
56.2 \%\end{array}$ & $\begin{array}{l}16 \\
100.0 \%\end{array}$ \\
\hline & Questioning & Count & & 8 & & \\
\hline & & $\begin{array}{l}\% \text { within } \\
\text { strategies }\end{array}$ & Monitoring & $57.1 \%$ & $42.9 \%$ & $100.0 \%$ \\
\hline & Reflecting & Count & & & & \\
\hline & & $\begin{array}{l}\% \text { within } \\
\text { strategies }\end{array}$ & Monitoring & $80.0 \%$ & $20.0 \%$ & $100.0 \%$ \\
\hline & Monitoring & Count & & & & \\
\hline & & $\begin{array}{l}\% \text { within } \\
\text { strategies }\end{array}$ & Monitoring & $75.0 \%$ & $25.0 \%$ & $100.0 \%$ \\
\hline & Summarizing & Count & & & & \\
\hline & & $\begin{array}{l}\% \text { within } \\
\text { strategies }\end{array}$ & Monitoring & $71.4 \%$ & $28.6 \%$ & $100.0 \%$ \\
\hline & $\begin{array}{l}\text { Looking for important } \\
\text { information }\end{array}$ & $\begin{array}{l}\text { Count } \\
\% \text { within } \\
\text { strategies }\end{array}$ & Monitoring & $\begin{array}{l}4 \\
66.7 \%\end{array}$ & $\begin{array}{l}2 \\
33.3 \%\end{array}$ & $\begin{array}{l}6 \\
100.0 \%\end{array}$ \\
\hline Total & & $\begin{array}{l}\text { Count } \\
\% \text { within } \\
\text { strategies }\end{array}$ & Monitoring & $\begin{array}{l}43 \\
63.2 \%\end{array}$ & $\begin{array}{l}25 \\
36.8 \%\end{array}$ & $\begin{array}{l}68 \\
100.0 \%\end{array}$ \\
\hline
\end{tabular}


As it is represented in Table (2), MP group significantly manipulated more monitoring strategies (63.2\%) while LP group utilized fewer strategies (36.8\%). Further exploration of the data also indicates the difference in percentages and in fact priority of MP group to LP group which is correspondingly prevalent in implementation of each single sub component of comprehension monitoring except for one case.

Delving into the details of use of subcomponents of comprehension monitoring strategies, it can be noticed that MP group made less use of determining word meaning strategy (43.8\%) while LP group employed more of this strategy (56.2\%). For the second strategy which is questioning, MP group implemented it for $(57.1 \%)$ whereas LP group used it for $(42.9 \%)$. The third strategy, reflecting, was

used $(80 \%)$ by MP group but the same strategy was deployed just (20\%). Monitoring, the fourth strategy in the subcomponents, was used (75\%) by MP group and (25\%) by LP group. Summarizing strategy has been implemented (71.4\%) by MP group and (28.6\%) by LP group. The last strategy which is looking for important information has been used (66.7\%) by MP group and $(33.3 \%)$ by LP group.

\subsection{Qualitative Results Concerning the Underlying Difference among MP and LP in Comprehension Monitoring}

According to Block (1992), the operation of comprehension monitoring can only be observable when failure of comprehension occurs. Therefore the result of think aloud protocol analysis describing how the proficient and less-proficient readers of the study performed their comprehension monitoring and manipulated each subcomponent strategy is depicted to show where similarities and differences lie.

\subsubsection{Think Aloud Protocol Analysis of More Proficient Readers}

It was clearly observed that some proficient readers were involved in planning which is an activity performed by good readers before reading a particular text (Pressley, 2002).

Example 1: "I want to skim through the whole text once from the beginning to the end to get the gist of the text."

The monitoring strategy of 'rereading' was clearly detected in her reading process.

Example 2: .." I read it (the paragraph) once, I didn't understand. I reread the last line and now it's clear to me."

Even after rereading the portion, some of them translated it into their mother tongue.

Example 4: "I translate those sentences which are harder."

Also, some participants of this group repeatedly attempted to make guesses of the meaning of new words by help of contextual clues rather than relying on dictionary a lot, except for being ensured.

Example 5: "Homogeneity? I don't know its meaning. I try looking into the following parenthesis to guess its meaning."

Apparently, frequency of unknown words made a burden for comprehending the passage therefore some tried out 'rereading' strategy to make up for that.

Monitoring strategy was also employed.

Example 6: "The first sentence was vague to me. I continued and read the second sentence. It helped me and made the first sentence's meaning complete and clear."

Example 7: "I didn't understand a couple of words in the above sentence. I prefer to continue."

Reflecting strategy was also manipulated while reading.

Example 8: "As I was reading, I was reflecting. I mean I was reflecting on its meaning to see what it is talking about."

They also made use of summarization.

Example 9: "This paragraph is generally talking about magnet, its design, etc."

Some of them made summarization after reading every couple of sentences to help them understand much better.

Example 10: "It is explaining about a part which is important and is inside the scanner."

More proficient readers also made use of self-questioning which another monitoring strategy is. Indeed some of them were deeply involved in reflecting and questioning to make sense of the text.

Example 11: "What does it mean by 'center'?"

Example 12: "What does it (third sentence) want to say?" 


\subsubsection{Think Aloud Protocol Analysis of Less Proficient Readers}

Most of less proficient readers looked up the meaning of almost all words in dictionary and tried to translate the sentences.

Example 1:"Now, I know the word, I try to translate them into Farsi but linking words is really hard for me."

Example 2: "I finished reading the passage and looked up the meaning of the words that I couldn't find. Now I got the meanings but I can't link the points. I must read it once more from beginning to the end."

Some of them also tried to make inferences and guesses based on what they read in a sentence.

Example 3:."Probably this process is called homogeneity which should be completed."

They employed summarization strategy, too.

Example 5: "All three parts are about magnet itself."

This participant also utilized her background knowledge in order to make comprehension easier.

\section{Discussion}

Concerning the proposed research question, the difference between MP and LP groups was verified through high percentages that MP group had in total comprehension monitoring use and results of the qualitative analysis. Based on these results we can safely reject the null hypothesis that there is no difference between MP and LP learners in terms of the quantity and quality of comprehension monitoring performance. What follows is the discussion of the main findings of this study.

It was discovered that MP's comprehension monitoring was different from LP's comprehension monitoring. In fact, all MP group members implemented planning strategies before commencing their reading enterprise. Specifically, majority of MP members had a goal in the beginning of their reading which was in some cases modified and new goals were set throughout the reading task. Another planning strategy which was prevalent among MP members was over viewing information in the text by which they tried to get a general picture of what the text was about. This is while members of the LP group started their reading process often without any planning beforehand, in that; there was no specific goal setting or over viewing information in the text, except activating background knowledge. Activating background knowledge happened when they were involved in actual reading of the material. Besides, they employed it when they couldn't make sense of a part of the passage.

One more point is that LPs explored the text word for word, sentence to sentence and paragraph to paragraph rather than taking a more holistic approach when dealing with the text. Instead, a majority of them started reading the passage from the first sentence and proceeded sentence to sentence while MP members had a much more holistic behavior when reading the text. These results are consistent with Hosenfeld (1977). In his study, the successful reader, for example, kept the meaning of the passage in mind while reading, read in broad phrases and skipped inconsequential or less important words. The unsuccessful reader on the other hand, lost the meaning of the sentences when decoded, read in short phrases, pondered over inconsequential words and seldom skipped words as unimportant.

Also while looking for the embedded error and as a result of not being able to detect the error at first prompt, LPs frequently declared that they lost the meaning of sentences since they were busy translating them word by word. This is consistent with Carrell's (1992) study which concluded that unskilled readers focus on decoding single words, fail to adjust their reading for different texts or purposes, and cannot make use of the strategies adequately.

Another finding to be discussed is that LPs looked for errors in those sentences (parts) that they had not understood. When they couldn't guess the error in their first or second attempt, they invested more time on incomprehensible parts rather than making sure of their correct comprehension of other sections. However, the error was in the part that they stated they had understood. It indicates that they didn't have a good judgment of their comprehension. This finding is consistent with Thorndike (1917, cited in Baker and Brown, 1986, p. 356) "The vise of the poor reader is to say the words to himself without actively making judgments concerning what they reveal." In his research, Thorndike found that many sixth graders did not spontaneously test their understanding; although they often felt that they have understood, while they had not." "Such behaviors reflect poor comprehension monitoring" (Baker and Brown, 1984, p. 356)

This difference between comprehension monitoring of MPs and LPs is also consistent with Block's (1992) study. Data from this study also revealed that more proficient readers seemed to be able to use inter-sentential information 
in the passage to check whether their initial hypothesis was appropriate or not. Similarly, less proficient readers seemed to monitor at word-level by using intra-sentential information. Additionally findings of the present study support Paris and Meyers's (1981) study in which successful readers or high proficient readers appear to use strategies more frequently than less successful or poor readers.

\section{Conclusion}

As discussed previously, the core interest of this study was to explore the manifestation of comprehension monitoring of Iranian EFL learners with high and low reading proficiency. This study was an attempt to explore the role of comprehension monitoring in reading comprehension ability of learners in an EFL context since it was observed that most studies have been conducted with native English speakers (Block, 1992). Also, comparing EFL learner's more limited environment, we see that comprehension monitoring is of more importance to them. Block also pinpoints the fact that L2 learners will probably encounter more linguistic difficulties and therefore need to "repair more gaps in their understanding" through comprehension monitoring [Block, 1992, p. 320].

In sum, the results of the present research indicated that less proficient readers perform comprehension monitoring poorly and less frequently in comparison with more proficient readers in that they were unsuccessful in examining whether the employed strategies were helpful in overcoming their reading problems. In this respect, the present study contributes to the existing body of knowledge in the domain of EFL learners comprehension monitoring. Finally, underlying differences in comprehension monitoring of more and less proficient readers has been shown. In this respect, too, this study supported previous research that has suggested that reading proficiency makes a difference in comprehension monitoring of language learners (Block, 1992; Paris \& Meyers, 1981). As the results of the present study revealed, more proficient readers perform more and efficient comprehension monitoring and knowing this fact helps teachers in accomplishing their challenging task of teaching English in EFL context where learners have less exposure to language compared to L1/ESL contexts.

\section{References}

Baker, L. (1985). How do we know when we don't understand? Standards for evaluating text comprehension. In D. L. Forrest-Pressley, G. E. MacKinnon, \& T. G. Wall (Eds.), Metacognition, cognition, and human performance, Theoretical perspectives (Vol. 1, pp. 155- 205). Orlando, Florida: Academic Press, Inc.

Baker, L., \& Brown. L. A. (1984). Metacognitive skills and reading. In P. D. Pearson (Ed.), Handbook of reading research (pp. 353-394). New York: Longman.

Baker, L., \& Zimlin, L. (1989). Instructional effects on children's use of two levels of standards for evaluating their $\begin{array}{llll}\text { comprehension. Journal of } & \text { Educational }\end{array}$ http://dx.doi.org/10.1037/0022-0663.81.3.340

Block, E. L. (1992). See how they read: Comprehension monitoring of L1 and L2 readers. TESOL Quarterly, 26(2), 319-343. http://dx.doi.org/10.2307/3587008

Brown, A. L. (1987). Metacognition, executive control, self-regulated and other more mysterious mechanisms. In F. E. Weinert, \& R. H. Kluwe (Eds.), Metacognition, motivation, and understanding (pp. 65-116). Hillsdale, NJ: Lawrence Erlbaum Associates.

Carrell, P. L. (1992). Awareness of text structure: Effects on recall. Language Learning, 42, 1-20. http://dx.doi.org/10.1111/j.1467-1770.1992.tb00698.x

Cromley, J. G. (2005). Metacognition, Cognitive Strategy Instruction, and Reading in Adult Literacy. In J. Comings, B. Garner, \& C. Smith (Eds.), Review of Adult Learning and Literacy (1st ed., pp. 187-220). Lawrence Erlbaum Associates.

Ehrlich, M. F., Remond, M., \& Tardieu, H. (1999). Processing of anaphoric devices in young skilled and less skilled comprehenders: Differences in metacognitive monitoring. Reading and Writing: An Interdisciplinary Journal, 11(1), 29-63.

European Commission. (2003). implementation of education and training 2010' work programme. Retrieved from http://ec.europa.eu/education/policies/2010/doc/opening_up_learning_and_citizenship_en_pdf.

Flavell, J. H. (1981). Cognitive monitoring. In W. P. Dickson (Ed.), Children's oral communication skills (pp. 35-60). New York: Academic Press. 
Garner, R. (1987b). Metacognition and reading comprehension. Norwood, NJ: Ablex.

Hacker, D. J. (1997). Comprehension monitoring of written discourse across early-to-middle adolescence. Reading and Writing: An Interdisciplinary Journal, 9, 207-240 http://dx.doi.org/10.1023/A:1007989901667

Hetherington, E. M., \& Parke, R. D. (1993). Child Psychology: Contemporary Viewpoint (4th Ed.). McGraw- Hill, Inc.

Hosenfeld, C. (1977). A preliminary investigation of the reading strategies of successful and nonsuccessful second language learners. System, 5(2), 110-123. http://dx.doi.org/10.1016/0346-251X(77)90087-2

Jiménez, R., García, G., \& Pearson, P. (1996). The reading strategies of bilingual Latin students who are successful English readers: Opportunities and obstacles. Reading Research Quarterly, 31, 90-112. http://dx.doi.org/10.1598/RRQ.31.1.5

Ling, F. (2000). Techniques for assessing comprehension monitoring. Post-Script, 1, 1.

Loizidou, Andri., \& Koutselini, M. (2007). Metacognitive Monitoring: an Obstacle and a Key To effective Teaching and Learning. Teachers and Teaching: Theory and Practice, 13(5), 499-519. http://dx.doi.org/10.1080/13540600701561711

Markman, E. (1985). Comprehension monitoring: Developmental and educational issues. In F. Chipman, W. Segal, \& R. Glaser (Eds.), Thinking and learning skills: Research and open questions (pp. 275-291). Hillsdale, NJ: Lawrence Erlbaum Associates.

Markman, E. (1981). Comprehension monitoring. In W. P. Dickson (Ed.), Children's oral communication skills (pp. 61-84), New York: Academic Press.

Oakhill, J. V., Hartt, J., \& Samols, D. (2005). Levels of comprehension monitoring and working memory in good and poor comprehenders. Reading and Writing: An Interdisciplinary Journal, 18, 657-686. http://dx.doi.org/10.1007/s11145-005-3355-z

Otero, J., \& Kintsch, W. (1992). Failures to detect contradictions in a text: What readers believe versus what they read. Psychological Science, 4, 229-235. http://dx.doi.org/10.1111/j.1467-9280.1992.tb00034.x

Stevenson, M., \& Han, F. (2008). Comprehension monitoring in first and foreign language reading. University of Sydney Papers in TESOL, 3, 73-110.

Paris, S. G., \& Myers, M. (1981). Comprehension monitoring, memory and study strategies of good and poor readers. Journal of Reading Behavior, 13, 5-22.

Pressley, M. (2002). Metacognition and self-regulated comprehension. In A. E. Farstrup, \& S. J. Samuels (Eds.), What research has to say about reading Instruction (3rd ed., pp. 291-309). Newark, DE: International Reading Association.

Pressley. M., \& Afflerbach, P. (1995). Verbal protocols of reading: The nature of constructively responsive reading. Hillsdale, NJ: Lawrence Erlbaum Associates.

Thorndike, E. L. (1917). Reading as reasoning: A study of mistakes in paragraph reading. Journal of Educational Psychology, 8, 323-332. http://dx.doi.org/10.1037/h0075325

UNESCO. (2002). Education (Athens, Gutenberg).

Wagoner, S. A. (1983). Comprehension monitoring: What it is and what we know about it. Reading Research Quarterly, 18, 328-346. http://dx.doi.org/10.2307/747392

Zabrucky, K., \& Ratner, H. H. (1992). Effects of passage type on comprehension monitoring and recall in good and poor readers. Journal of Reading Behaviour, 24(3), 373-391.

Zinar, S. (2000). The relative contributions of word identification skill and comprehension- monitoring behavior to reading comprehension ability. Contemporary Educational Psychology, 25, 363-377. http://dx.doi.org/10.1006/ceps.2000.1024

Zipke, M. (2007). Metalinguisitc Instruction improves third graders' reading comprehension. Unpublished doctoral dissertation, The City University of New York. 